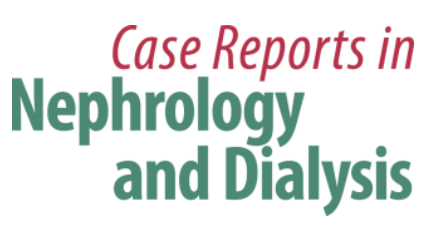

Case Rep Nephrol Dial 2019;9:149-157

DOI: 10.1159/000503951

Published online: November 13, 2019

(C) 2019 The Author(s)

Published by S. Karger AG, Basel

www.karger.com/cnd

This article is licensed under the Creative Commons Attribution-NonCommercial 4.0 International License (CC BY-NC) (http://www.karger.com/Services/OpenAccessLicense). Usage and distribution for commercial purposes requires written permission.

\title{
Daratumumab for Treatment of Antibody-Mediated Rejection after ABO-Incompatible Kidney Transplantation
}

\author{
Davide Spica $^{\mathrm{a}} \quad$ Till Junker $^{\mathrm{b}} \quad$ Michael Dickenmann $^{\mathrm{a}}$ Stefan Schaub $^{\mathrm{a}, \mathrm{c}, \mathrm{d}}$ \\ Jürg Steiger ${ }^{a, c}$ Tanja Rüflie Jörg Halter ${ }^{b}$ Helmut Hopfer ${ }^{f}$ \\ Andreas Holbro ${ }^{\text {b, e }}$ Patricia Hirt-Minkowski ${ }^{a}$ \\ aTransplantation Immunology and Nephrology, University Hospital Basel, \\ Basel, Switzerland; 'bivision of Hematology, Department of Medicine, University Hospital \\ Basel, Basel, Switzerland; 'Transplantation Immunology, Department of Biomedicine, \\ University of Basel, Basel, Switzerland; dHLA-Diagnostic and Immunogenetics, Department \\ of Laboratory Medicine, University Hospital Basel, Basel, Switzerland; eBlood Transfusion \\ Service, Swiss Red Cross, Basel, Switzerland; Institute for Pathology, University Hospital \\ Basel, Basel, Switzerland
}

\section{Keywords}

Antibody-mediated rejection $\cdot \mathrm{ABO}$-incompatible kidney transplantation $\cdot$ Anti-rejection therapy · Daratumumab

\begin{abstract}
We report the effectiveness of daratumumab, a human $\lg G \kappa$ monoclonal antibody targeting CD38 on plasma cells, for therapy-refractory antibody-mediated rejection (AMR) due to blood group antibodies in a 59-year-old man who received a living ABO-incompatible kidney transplantation. Standard treatment options for AMR due to blood group antibodies including immunoadsorption, lymphocyte depletion with anti-human T-lymphocyte globulins, intravenous methylprednisolone pulses and eculizumab limited tissue injury, however failed to sufficiently suppress blood group antibody production. After administration of daratumumab as a rescue
\end{abstract}




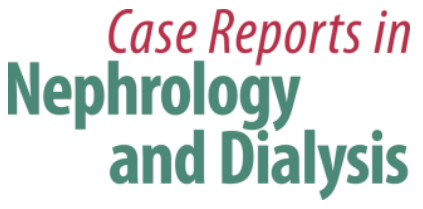

Case Rep Nephrol Dial 2019;9:149-157

DOI: $10.1159 / 000503951$

(c) 2019 The Author(s). Published by S. Karger AG, Basel www.karger.com/cnd

Spica et al.: Daratumumab for Treatment of Antibody-Mediated Rejection after ABOIncompatible Kidney Transplantation

therapy, blood group antibody titers decreased and remained at low levels without further immunoadsorption and allowed kidney graft function to recover.

(C) 2019 The Author(s)

Published by S. Karger AG, Basel

\section{Introduction}

Kidney transplantation is the therapy of choice for many patients with end-stage renal disease. Pretransplant risk stratification and modern immunosuppression have led to striking advances over the past decades, resulting in better long-term graft survival [1-4]. Nevertheless, there still exist important unmet clinical needs and problems to be solved for kidney transplant recipients [5-7]. Antibody-mediated rejection (AMR) has been recognized as one of the most important causes of graft loss [8-10]. Although less frequent than antibodies directed against human leukocyte antigens (i.e., donor specific HLA-antibodies [DSA]) [11], antibodies against $\mathrm{ABO}$ blood group antigens can be the cause of AMR [12]. In a meta-analysis, which included 26 centers, describing 1,346 ABO-incompatible kidney transplant patients, AMR within the first year post-transplant was more common and occurred with a fourfold risk compared to 4,943 center-matched controls, who were ABO-compatible [12]. To date, there are no US Food and Drug Administration (FDA)-approved immunosuppressive drugs for either prevention or treatment of AMR [13]. The only FDA-approved drugs for treatment of acute rejection are polyclonal anti-T lymphocyte globulins [6]. Several additional agents have been employed as off-label for the treatment of AMR with variable effectiveness such as intravenous immunoglobulins, rituximab, bortezomib, and eculizumab as well as removing of circulating anti-HLA antibodies and blood group antibodies by plasmapheresis/plasma exchange or immunoadsorption $[13,14]$. Thus, our armamentarium to treat AMR is still incomplete. For this reason, new therapeutic options to reduce the burden of AMR are urgently needed.

Daratumumab is a human monoclonal IgGk antibody targeting the glycoprotein CD38 which is expressed on plasma cells and induces cell death and apoptosis through different immune effector mechanisms such as complement-mediated cytotoxicity, antibody-mediated cytotoxicity, antibody-dependent phagocytosis and direct induction of apoptosis [15]. Based on data of the MMY2002 (SIRIUS) [16] and the GEN501 [17] studies, daratumumab has emerged as a new option in therapy-refractory multiple myeloma and was approved for treatment of multiple myeloma in 2015 [18]. As CD38 is also expressed on nonmalignant plasma cells, it seems obvious to test daratumumab as a rescue therapy in other diseases with pathogenetically involved, antibody-producing plasma cells after failure of established therapies. Thus, daratumumab has been used in other settings where antibody production by plasma cells is the pathophysiologic key feature. The effective treatment of refractory post-transplant autoimmune hemolytic anemia after allogenic hematopoietic stem cell transplantation (HSCT) was reported by Schuetz et al. [19] in a small case series of 3 patients ( 1 adult, 2 pediatric cases). Furthermore, daratumumab was used successfully for treatment of delayed redcell engraftment (i.e., pure red cell aplasia) due to ABO incompatibility after allogenic HSCT [20]. These conditions share the central role of deleterious blood group antibodies produced by nonmalignant plasma cells that target and destroy allogenic tissue. In all reported cases, depletion of the plasma cells by daratumumab resulted in resolution of red blood cell destruction $[19,20]$. 


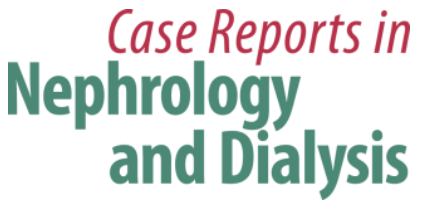

Case Rep Nephrol Dial 2019;9:149-157

DOI: $10.1159 / 000503951$

(c) 2019 The Author(s). Published by S. Karger AG, Basel www.karger.com/cnd

Spica et al.: Daratumumab for Treatment of Antibody-Mediated Rejection after ABOIncompatible Kidney Transplantation

As therapeutic options for AMR are limited, an anti-CD38 agent such as daratumumab may be a new treatment option to be evaluated in patients with no response to so far utilized anti-rejection therapies for AMR.

\section{Case Report}

A 59-year-old man with end-stage renal disease due to IgA nephropathy received a living kidney donation from his 64-year-old HLA-haploidentical sister. HLA antibody screening before transplantation performed by Luminex single HLA antigen beads (LabScreen SA; One Lambda Inc., CA, USA) showed no DSA. Because of major ABO incompatibility (i.e., recipient with blood group $\mathrm{B}$ and donor with blood group $\mathrm{A}$ ), the recipient was treated with rituximab $375 \mathrm{mg} / \mathrm{m}^{2}$ for B-cell depletion 4 weeks before transplantation. Baseline immunosuppressive therapy with tacrolimus (tac) with a goal to reach a trough level of 8-10 $\mu \mathrm{g} / \mathrm{L}$ and mycophenolate mofetil (MMF) twice daily $500 \mathrm{mg}$ was started 2 weeks before transplantation and extended by prednisone with an initial dose of $30 \mathrm{mg}$ per day on day -6 (i.e., 6 days before transplantation). During the in-hospital stay, tac trough levels were measured three times per week (i.e., within the first 37 days post-transplant), followed by weekly measurements thereafter. In addition, from day -5 to -1 (i.e., from 5 days to 1 day before transplantation) the patient received five sessions of immunoadsorption with a Glycosorb ${ }^{\circledR}$ column (Glycorex Transplantation $\mathrm{AB}$, Lund, Sweden) to remove circulating anti-A blood group antibodies. When starting immunoadsorption, anti-A IgM isohemagglutinin and anti-A IgG titers were 1:8 and 1:32, respectively. On the day of transplantation, anti-A IgM isohemagglutinin and anti-A IgG titers had been reduced to $1: 2$ and 1:4, respectively (Fig. 1). Induction immunosuppression consisted of basiliximab (i.e., $20 \mathrm{mg}$ at day 0 , followed by $20 \mathrm{mg}$ at day 4 ) and baseline immunosuppressive therapy with tac, MMF, and prednisone was continued during the whole course. This treatment approach reflects the standard procedure in ABO-incompatible kidney transplantation at our center as described before [21]. Serum creatinine levels dropped from 604 to $189 \mu \mathrm{mol} / \mathrm{L}$ at day 4 (Fig. 1), reaching an adequate baseline estimated GFR (eGFR) of 33 $\mathrm{mL} / \mathrm{min} / 1.73 \mathrm{~m}^{2}$ calculated by CKD-EPI formula, taking into account the patient's/donor's age, weight mismatch, and kidney function of the sister before donation (i.e., eGFR of 94 $\mathrm{mL} / \mathrm{min} / 1.73 \mathrm{~m}^{2}$ ).

In the first days after transplantation, anti-A IgM and anti-A IgG isohemagglutinin titers remained low (maximal 1:2 and 1:4, respectively). On day 6, both titers began to rise and reached a maximum of 1:64, which was followed by a sudden drop in kidney graft function (decrease in eGFR from 33 to $14 \mathrm{~mL} / \mathrm{min} / 1.73 \mathrm{~m}^{2}$ on day 10) (Fig. 1). A biopsy on day 7 showed mild diffuse acute tubular damage (Fig. 2a). By immunofluorescence, both IgM and C3c deposition was seen in the peritubular capillaries in addition to the C4d positivity usually seen in AB0-incompatible graft biopsies suggesting very recent antibody-mediated complement activation (Fig. $2 \mathrm{~b}-\mathrm{d}$ ). In the context of rising anti-A isohemagglutinins and declining graft function, these findings were interpreted as a very early episode of AMR due to anti-A blood group antibodies. Immunoadsorption was restarted on day 8, effectively removing the circulating anti-A blood group antibodies (Fig. 1). To suppress further antibody production, anti-human T-lymphocyte globulins (i.e., totally seven infusions with a dosage between 2 and $4 \mathrm{mg} / \mathrm{kg}$ of body weight on day 9 , from day 14 to 18 , and on day 20) as well as high-dose intravenous methylprednisolone (i.e., totally five pulses between day 7 and 11) were administrated. Afterwards, prednisone dosed $0.5 \mathrm{mg} / \mathrm{kg}$ body weight was continued. Additionally, eculizumab, a monoclonal antibody that targets complement C5 (i.e., three infusions of 900 


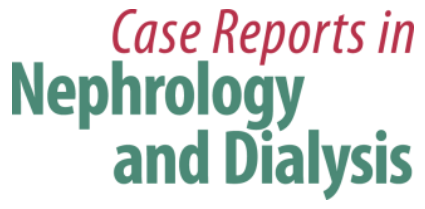

Case Rep Nephrol Dial 2019;9:149-157

DOI: $10.1159 / 000503951$

(c) 2019 The Author(s). Published by S. Karger AG, Basel www.karger.com/cnd

Spica et al.: Daratumumab for Treatment of Antibody-Mediated Rejection after ABOIncompatible Kidney Transplantation

mg per week on days 12, 19 and 26, respectively), was administrated to limit destruction of endothelial cells by complement-dependent cytotoxicity. So far, our approach for treatment of AMR stabilized kidney graft function with low eGFR levels between 18 and $20 \mathrm{~mL} / \mathrm{min} / 1.73$ $\mathrm{m}^{2}$. Unfortunately, anti-A antibody titers immediately rose again after discontinuation of immunoadsorption on day 19 to IgM isohemagglutinin titers of 1:32 and IgG of 1:32 on day 23 post-transplant. Thus, immunoadsorption of anti-A blood group antibodies was resumed and anti-A antibodies could successfully be removed. When immunoadsorption was stopped once again on day 26 , anti-A antibody titers rose repeatedly, reaching IgM isohemagglutinin titers of 1:16 and IgG of 1:16, respectively on day 29, as summarized in Figure 1.

To prevent long-term dependence of immunoadsorption and eventually graft failure and due to the lack of effectiveness of the so far established combined therapy, daratumumab was administrated as a rescue therapy at a dose of $16 \mathrm{mg}$ per kg of body weight in weekly intervals beginning on day 30 after kidney transplantation. The patient gave his consent after information about the experimental approach. Eculizumab was discontinued avoiding interference with daratumumab by possibly blocking complement-mediated cytotoxicity of the targeted plasma cells, which is considered an important mechanism of action of daratumumab. Within $72 \mathrm{~h}$ after the first dose of daratumumab, the pathogenic IgM isohemagglutinins started to fall continuously without any further immunoadsorption. In total, the patient received six infusions of daratumumab, without any severe drug-related adverse event. Two weeks after administration of the last daratumumab infusion on day 65 , the anti-A IgM isohemagglutinin and anti-A IgG titers were 1:1 and 1:2, respectively and persisted at low levels the following weeks. As binding of daratumumab to CD38 on red blood cells can affect measurement of anti-A IgG antibodies, anti-A IgG titers were validated after incubation with dithiothreitol as described previously [22]. A biopsy of the kidney graft on day 73 post-transplant showed no signs of acute rejection (image not shown). The patient's graft function nearly recovered to baseline with eGFR levels at $27-32 \mathrm{~mL} / \mathrm{min} / 1.73 \mathrm{~m}^{2}$. To note, no further immunoadsorption was necessary after initiation of daratumumab.

\section{Discussion}

To the best of our knowledge, this is the first report of successful administration of daratumumab for treatment of therapy-refractory AMR in kidney transplantation. In the context of rising anti-A isohemagglutinin titers right before graft function deterioration, early active ABO blood group AMR was strongly suggested. In this case, it was confirmed by the histologic findings of tissue injury (unexplained acute tubular injury) and evidence of interaction of IgM antibodies with vascular endothelial cells on the peritubular capillaries with concomitant activation and deposition of complement factor C3c. This provided the pathogenetic linkage between the rising anti-A isohemagglutinins and kidney transplant injury. Thus, we interpreted the early rise in anti-A isohemagglutinin titers as clinically relevant. Because of the evidence for early anti-A isohemagglutinins-mediated tissue injury, we did not screen for de novo DSA in this patient, who was tested negative for pre-transplant DSA timely before transplantation and treated with rituximab for desensitization 4 weeks prior to transplantation.

In summary, our patient developed early active AMR caused by anti-A IgM isohemagglutinins after kidney transplantation from his ABO-incompatible sister despite following established therapeutic strategies for ABO-incompatible kidney transplantation [21], and immediate treatment with anti-human T-lymphocyte globulins, high-dose methylprednisolone, blocking the complement-mediated effector mechanisms of tissue injury by eculizumab and 


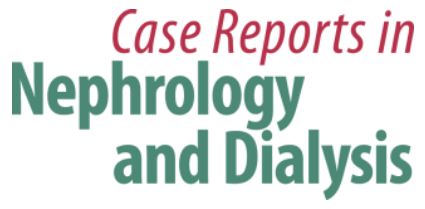

Case Rep Nephrol Dial 2019;9:149-157

DOI: $10.1159 / 000503951$

(c) 2019 The Author(s). Published by S. Karger AG, Basel www.karger.com/cnd

Spica et al.: Daratumumab for Treatment of Antibody-Mediated Rejection after ABOIncompatible Kidney Transplantation

immunoadsorption for the removal of circulating blood group antibodies. Although this approach prevented further decrease in allograft function and possibly graft loss, it did not induce resolution of the rejection process due to the ongoing production of anti-A blood group antibodies.

Based on the efficacy of daratumumab in the treatment of post-HSCT autoimmune hemolytic anemia and pure red cell aplasia following ABO-incompatible HSCT, we hypothesized that direct targeting and depletion of the antibody-producing plasma cells by daratumumab could be a treatment option for our patient in order to avoid graft failure. Bortezomib has been described for the treatment of refractory AMR in kidney transplantation in several cases [23, 24], which is a less directed approach to target plasma cells. However, we were reluctant to give bortezomib because of the risk of severe peripheral neuropathy as a limiting side effect in a patient who had been operated for spinal stenosis prior to kidney transplantation.

In fact, after the first dose of daratumumab, the suspected pathogenic IgM isohemagglutinins continuously fell without any additional immunoadsorption. The rapid response could be explained by the relatively short half-life of IgM antibodies of approximately 5 days. Although we cannot prove the causality between daratumumab and the reduction in antibody titers - which could also be part of the natural course after ABO-incompatible kidney transplantation - the timely coincidence suggests the decrease in antibody titers to be a direct consequence of daratumumab. Further, rising blood group antibody titers after transplantation do not necessarily need to reflect subsequent allograft dysfunction or AMR, because allograft tolerance of the blood group antibodies can be observed after ABO-incompatible kidney transplantation. Even though a rise in blood group antibody titers can occur early in the post-transplant course (i.e., from the first week ongoing), titers normally rise within 4-6 weeks after transplantation, and "pure rebound" is typically not associated with graft dysfunction and histologic signs of early active AMR [25-27].

Moreover, there could be an influence of the complex antirejection therapy (steroid pulses, anti-thymocyte globulins, eculizumab) administrated prior to daratumumab on the reduction of anti-A blood group antibodies and resolution of tissue damage. In a complex clinical situation where a new therapeutic option is evaluated as a rescue therapy, it is impossible in a single case to prove causality of the rescue therapy (i.e., therapeutic effect of a specific treatment). One explanation in our case may be the fact that, despite those initial treatments, antiA IgM titers rose again two times immediately after discontinuation of immunoadsorption and, in contrary, fell right after the first daratumumab administration without further immunoadsorption assuming a much greater effect of daratumumab on anti-A blood group antibody suppression. In addition, the level of blood group antibodies measured in the blood does not necessarily reflect the burden of antibodies bound to the graft. However, the second allograft biopsy performed on day 73 post-transplant showed no signs of acute rejection, including no more deposition of IgM and complement C3c. Concerns about immunomodulatory effects of daratumumab occurred before infusion, as the drug targets CD38-expressing cells through a variety of immune-mediated mechanisms [15]. Krejcik et al. [28] studied peripheral blood and bone marrow of patients with relapsed/refractory myeloma which were treated with daratumumab from two different monotherapy studies. They showed that daratumumab depleted CD38-positive immune regulatory cells and promoted T-cell expansion, and demonstrated further T-cell changes, which they highlighted as "skew of T-cell repertoire in multiple myeloma" [28]. In transplantation, these immunomodulatory effects of the anti-CD38 drug could represent additional mechanisms of interaction which may trigger cellular rejection and, thus, act against the allograft. Thus, it is important to mention that the patient developed no acute cellular rejection during the course and after treatment with daratumumab proven 
by biopsy. Further, the medication was well tolerated by the patient, and no severe infections were observed.

\section{Conclusion}

Our case report suggests that daratumumab may be a promising option as a rescue therapy for therapy-refractory AMR in the context of ABO-incompatible kidney transplantation. As large clinical trials evaluating new treatment regimens for AMR are unlikely to be performed in the near future, case reports may be a more practical way to evaluate treatment response. Furthermore, daratumumab may also be considered part of the preparative regimen before ABO-incompatible kidney transplantation with or without rituximab in order to directly target blood group antibody-producing plasma cells with the potential to avoid immunoadsorption. Nevertheless, the immunomodulatory effects of daratumumab need to be taken into account. To address this issue, further studies are warranted.

\section{Statement of Ethics}

The research was conducted in accordance with the World Medical Association Declaration of Helsinki (https://www.wma.net/policies-post/wma-declaration-of-helsinki-ethicalprinciples-for-medical-research-involving-human-subjects/). The participant gave written informed consent for publication of this case report.

\section{Disclosure Statement}

The authors of this article declare no conflicts of interest as described by Karger Case Reports in Nephrology and Dialysis.

\section{Funding Sources}

Daratumumab therapy was funded by Janssen-Cilag AG, Zug, Switzerland. P.H.-M. is supported by the Alfred und Erika Bär-Spycher-Stiftung.

\section{Author Contributions}

All authors contributed equally to the literature review and the text of the manuscript. D.S., P.H.-M. and A.H. were responsible for the patient care and treatment.

\section{References}

1 Knoll G. Trends in kidney transplantation over the past decade. Drugs. 2008;68 Suppl 1:3-10.

2 Stegall MD, Park WD, Dean PG, Cosio FG. Improving long-term renal allograft survival via a road less traveled by. Am J Transplant. 2011 Jul;11(7):1382-7.

3 Lamb KE, Lodhi S, Meier-Kriesche HU. Long-term renal allograft survival in the United States: a critical reappraisal. Am J Transplant. 2011 Mar;11(3):450-62. 
4 Matas AJ, Smith JM, Skeans MA, Thompson B, Gustafson SK, Stewart DE, et al. OPTN/SRTR 2013 Annual Data Report: kidney. Am J Transplant. 2015 Jan;15(S2 Suppl 2):1-34.

5 Stegall MD, Morris RE, Alloway RR, Mannon RB. Developing New Immunosuppression for the Next Generation of Transplant Recipients: The Path Forward. Am J Transplant. 2016 Apr;16(4):1094-101.

6 O'Connell PJ, Kuypers DR, Mannon RB, Abecassis M, Chadban SJ, Gill JS, et al. Clinical Trials for Immunosuppression in Transplantation: The Case for Reform and Change in Direction. Transplantation. 2017 Jul;101(7):1527-34.

7 Walsh L, Dinavahi R. Current unmet needs in renal transplantation: a review of challenges and therapeutics. Front Biosci (Elite Ed). 2016 Jan;8(1):1-14.

8 Einecke G, Sis B, Reeve J, Mengel M, Campbell PM, Hidalgo LG, et al. Antibody-mediated microcirculation injury is the major cause of late kidney transplant failure. Am J Transplant. 2009 Nov;9(11):2520-31.

9 Gaston RS, Cecka JM, Kasiske BL, Fieberg AM, Leduc R, Cosio FC, et al. Evidence for antibody-mediated injury as a major determinant of late kidney allograft failure. Transplantation. 2010 Jul;90(1):68-74.

10 Sellarés J, de Freitas DG, Mengel M, Reeve J, Einecke G, Sis B, et al. Understanding the causes of kidney transplant failure: the dominant role of antibody-mediated rejection and nonadherence. Am J Transplant. 2012 Feb;12(2):388-99.

11 Colvin RB, Smith RN. Antibody-mediated organ-allograft rejection. Nat Rev Immunol. 2005 Oct;5(10):80717.

12 de Weerd AE, Betjes MG. ABO-Incompatible Kidney Transplant Outcomes: A Meta-Analysis. Clin J Am Soc Nephrol. 2018 Aug;13(8):1234-43.

13 Archdeacon P, Chan M, Neuland C, Velidedeoglu E, Meyer J, Tracy L, et al. Summary of FDA antibodymediated rejection workshop. Am J Transplant. 2011 May;11(5):896-906.

14 Davis S, Cooper JE. Acute antibody-mediated rejection in kidney transplant recipients. Transplant Rev (Orlando). 2017 Jan;31(1):47-54.

15 van de Donk NW, Usmani SZ. CD38 Antibodies in Multiple Myeloma: Mechanisms of Action and Modes of Resistance. Front Immunol. 2018 Sep;9:2134.

16 Lonial S, Weiss BM, Usmani SZ, Singhal S, Chari A, Bahlis NJ, et al. Daratumumab monotherapy in patients with treatment-refractory multiple myeloma (SIRIUS): an open-label, randomised, phase 2 trial. Lancet. 2016 Apr;387(10027):1551-60.

17 Lokhorst HM, Plesner T, Laubach JP, Nahi H, Gimsing P, Hansson M, et al. Targeting CD38 with Daratumumab Monotherapy in Multiple Myeloma. N Engl J Med. 2015 Sep;373(13):1207-19.

18 Costello C. An update on the role of daratumumab in the treatment of multiple myeloma. Ther Adv Hematol. 2017 Jan;8(1):28-37.

19 Schuetz C, Hoenig M, Moshous D, Weinstock C, Castelle M, Bendavid M, et al. Daratumumab in lifethreatening autoimmune hemolytic anemia following hematopoietic stem cell transplantation. Blood Adv. 2018 Oct;2(19):2550-3.

20 Chapuy CI, Kaufman RM, Alyea EP, Connors JM. Daratumumab for Delayed Red-Cell Engraftment after Allogeneic Transplantation. N Engl J Med. 2018 Nov;379(19):1846-50.

21 Oettl T, Halter J, Bachmann A, Guerke L, Infanti L, Oertli D, et al. ABO blood group-incompatible living donor kidney transplantation: a prospective, single-centre analysis including serial protocol biopsies. Nephrol Dial Transplant. 2009 Jan;24(1):298-303.

22 Chapuy CI, Nicholson RT, Aguad MD, Chapuy B, Laubach JP, Richardson PG, et al. Resolving the daratumumab interference with blood compatibility testing. Transfusion. 2015 Jun;55(6 Pt 2):1545-54.

23 Sureshkumar KK, Hussain SM, Marcus RJ, Ko TY, Khan AS, Tom K, et al. Proteasome inhibition with bortezomib: an effective therapy for severe antibody mediated rejection after renal transplantation. Clin Nephrol. 2012 Mar;77(3):246-53.

24 Lee J, Kim BS, Park Y, Lee JG, Lim BJ, Jeong HJ, et al. The Effect of Bortezomib on Antibody-Mediated Rejection after Kidney Transplantation. Yonsei Med J. 2015 Nov;56(6):1638-42.

25 Fehr T, Stussi G. ABO-incompatible kidney transplantation. Curr Opin Organ Transplant. 2012 Aug;17(4):376-85.

26 Shah BV, Rajput P, Virani ZA, Warghade S. Baseline Anti-blood Group Antibody Titers and their Response to Desensitization and Kidney Transplantation. Indian J Nephrol. 2017 May-Jun;27(3):195-8.

27 Ishida H, Kondo T, Shimizu T, Nozaki T, Tanabe K. Postoperative rebound of antiblood type antibodies and antibody-mediated rejection after ABO-incompatible living-related kidney transplantation. Transpl Int. 2015 Mar;28(3):286-96.

28 Krejcik J, Casneuf T, Nijhof IS, Verbist B, Bald J, Plesner T, et al. Daratumumab depletes CD38+ immune regulatory cells, promotes T-cell expansion, and skews T-cell repertoire in multiple myeloma. Blood. 2016 Jul;128(3):384-94

A. Holbro and P. Hirt-Minkowski contributed equally to this article 


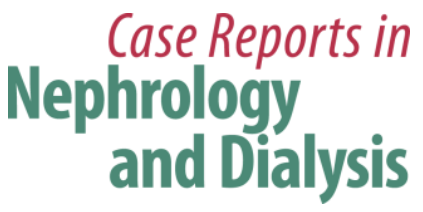

Case Rep Nephrol Dial 2019;9:149-157

DOI: 10.1159/000503951

(c) 2019 The Author(s). Published by S. Karger AG, Basel www.karger.com/cnd

Spica et al:: Daratumumab for Treatment of Antibody-Mediated Rejection after ABOIncompatible Kidney Transplantation

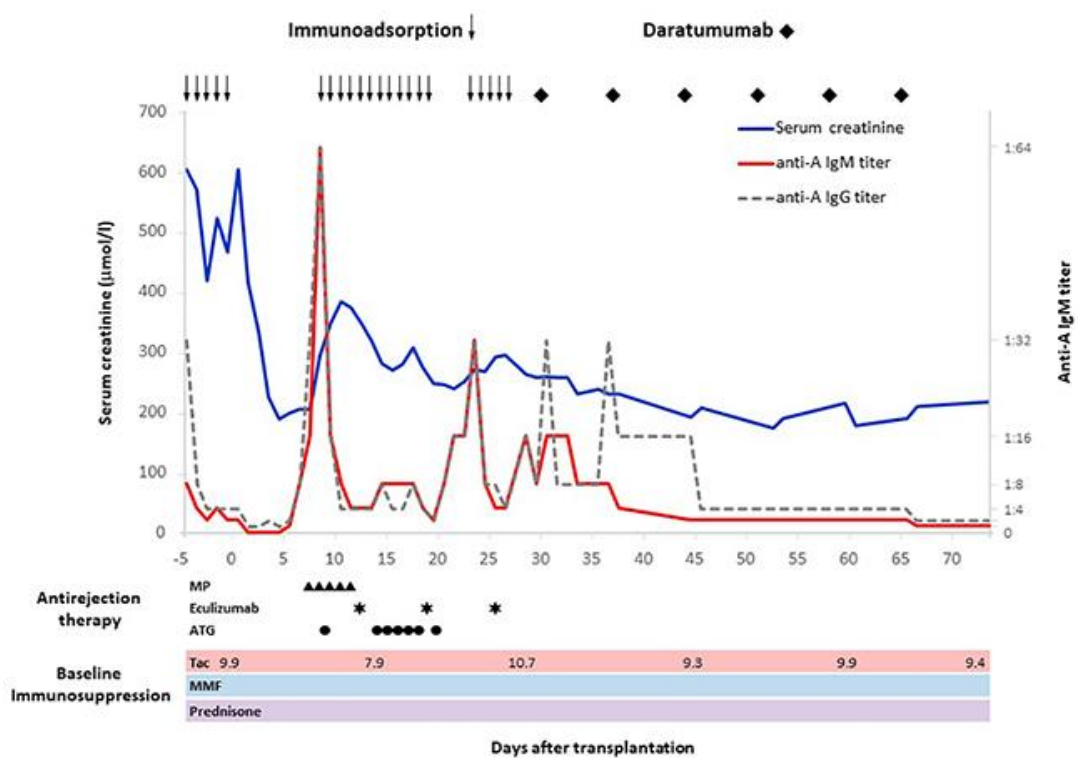

Fig. 1. Course of the 59-year-old patient treated with daratumumab for antibody-mediated acute rejection after ABO-incompatible kidney transplantation. Daratumumab was administered at a dose of $16 \mathrm{mg}$ per kg of body weight in weekly intervals. MP, methylprednisolone (pulse doses between 250-500 mg). Eculizumab (three infusions of $900 \mathrm{mg}$ per week on days 12, 19, and 26, respectively). ATG, anti-human Tlymphocyte globulins (i.e., totally seven infusions with a dosage between $2-4 \mathrm{mg} / \mathrm{kg}$ of body weight). Tac, tacrolimus (goal trough level of 8-10 $\mu \mathrm{g} / \mathrm{L}$ ). Tac trough levels are indicated bi-weekly \pm 4 days and illustrate selected time points of measurement post-transplant. MMF, mycophenolate mofetil (twice daily 500 mg). Prednisone (30-50 mg daily). 


\section{Case Reports in Nephrology and Dialysis}

Case Rep Nephrol Dial 2019;9:149-157 DOI: 10.1159/000503951

(c) 2019 The Author(s). Published by S. Karger AG, Basel www.karger.com/cnd

Spica et al: Daratumumab for Treatment of Antibody-Mediated Rejection after ABOIncompatible Kidney Transplantation
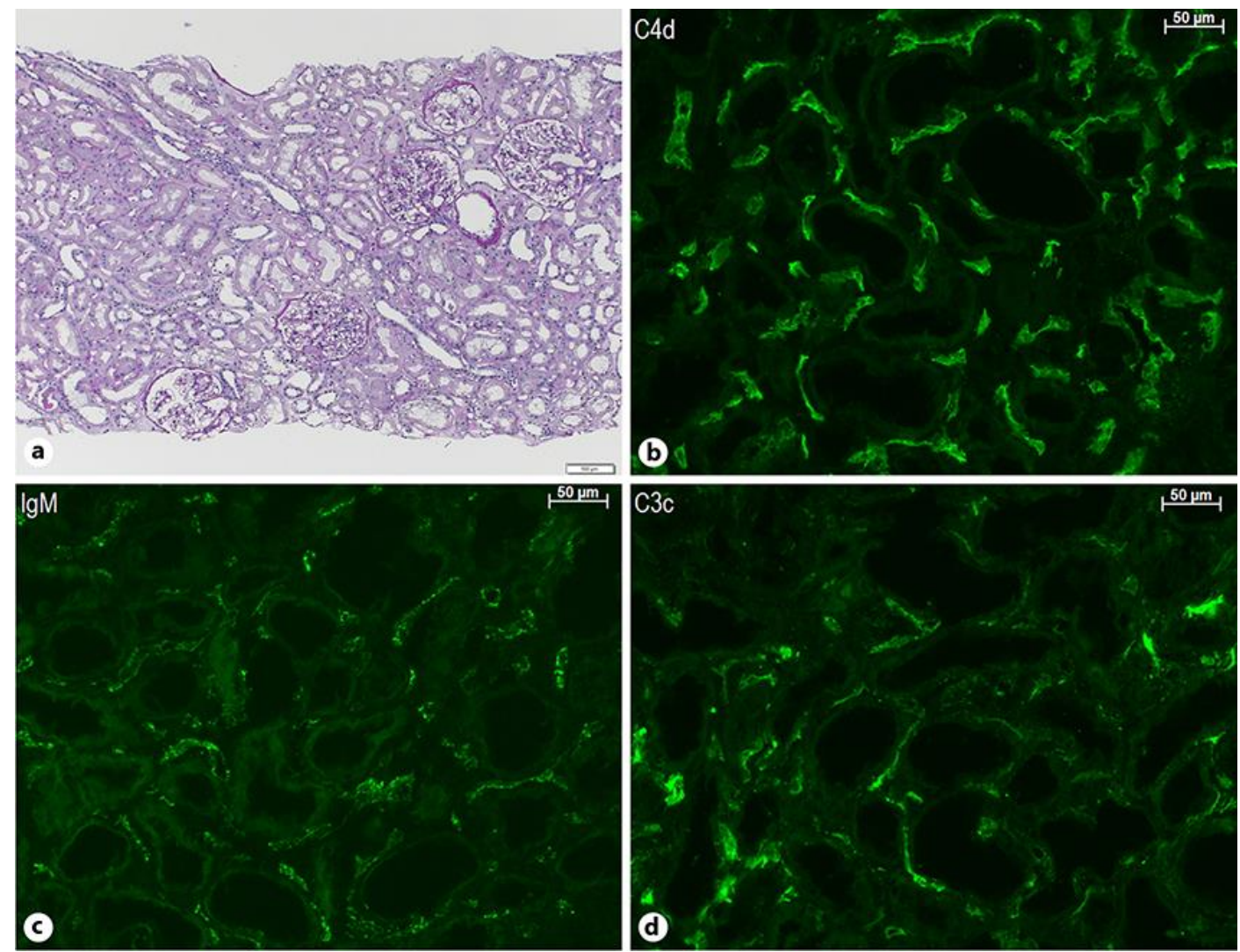

Fig. 2. Kidney transplant biopsy on day 7. a Conventional histology showed diffuse mild acute tubular damage with widened tubular lumina and mild interstitial edema. PAS stain, original magnification $\times 100$. b-d Immunofluorescence of cryosections demonstrated diffuse linear complement C4d staining along the peritubular capillaries (b), but also a more granular deposition of IgM (c) and complement C3c (d), indicating a very recent antibody interaction with the endothelium. Incubations for IgA and IgG were negative (not shown). Indirect (b) and direct (c, d) immunofluorescence with FITC-labeled antibodies. Original magnification $\times 200$. 